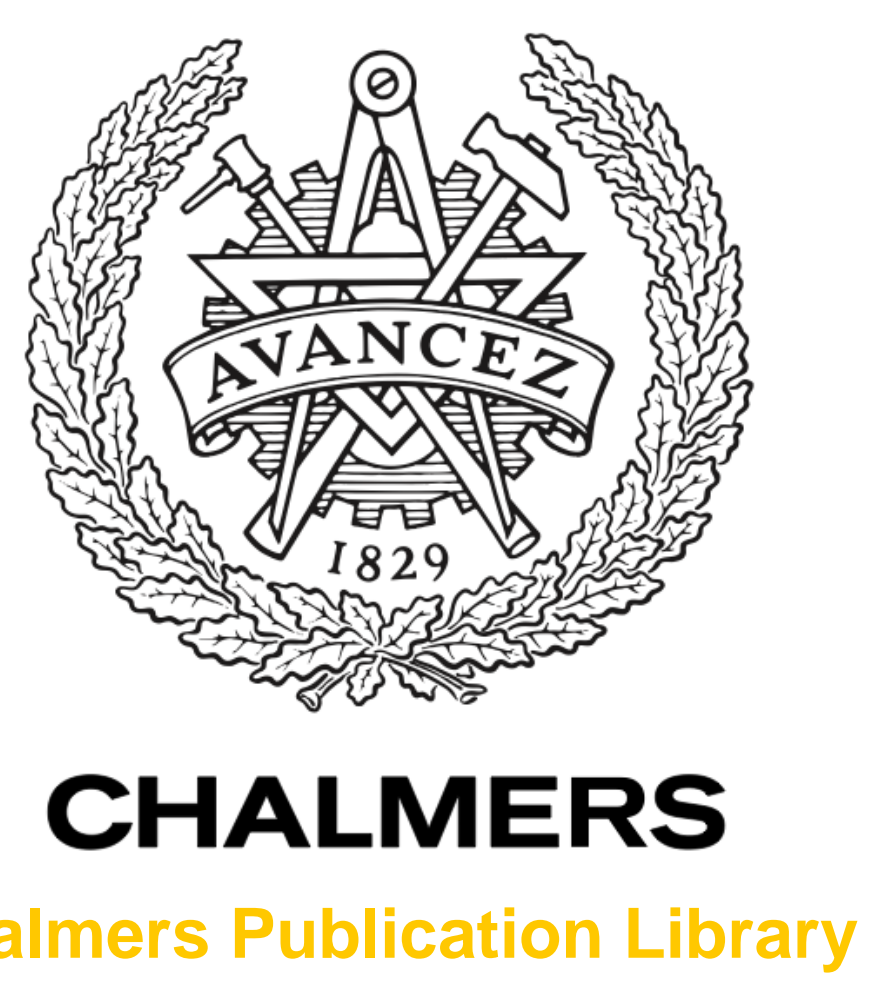

Chalmers Publication Library

\title{
What tensions obstruct an alignment between project and environmental management practices?
}

This document has been downloaded from Chalmers Publication Library (CPL). It is the author's version of a work that was accepted for publication in:

Engineering, Construction and Architectural Management (ISSN: 0969-9988)

Citation for the published paper:

Gluch, P. ; Räisänen, C. (2012) "What tensions obstruct an alignment between project and environmental management practices?". Engineering, Construction and Architectural

Management, vol. 19(2), pp. 127-140.

http://dx.doi.org/10.1108/09699981211206070

Downloaded from: http://publications.lib.chalmers.se/publication/155426

Notice: Changes introduced as a result of publishing processes such as copy-editing and formatting may not be reflected in this document. For a definitive version of this work, please refer to the published source. Please note that access to the published version might require a subscription.

Chalmers Publication Library (CPL) offers the possibility of retrieving research publications produced at Chalmers University of Technology. It covers all types of publications: articles, dissertations, licentiate theses, masters theses, conference papers, reports etc. Since 2006 it is the official tool for Chalmers official publication statistics. To ensure that Chalmers research results are disseminated as widely as possible, an Open Access Policy has been adopted.

The CPL service is administrated and maintained by Chalmers Library. 


\title{
What tensions obstruct an alignment between project and environmental management practices?
}

\author{
Pernilla Gluch and Christine Räisänen
}

Construction Management, Chalmers University of Technology, S-41296 Göteborg, Sweden.

\begin{abstract}
Purpose - Using an activity theory lens, the interrelationships between project practice and environmental management is examined. The focus is on tensions that occur between human agents and material objects within a motive-directed, historically situated activity system, namely that of managing environmental issues in projects.

Design/methodology/approach - Case studies of two large infrastructure projects were conducted 2003-2004 and 2008. The studies comprised on-site observations, text analyses, 20 semi-structured interviews and one group interview. Time was spent on the construction site to become familiarised with the context and the practices of the project community. Fifteen weekly environmental site inspections were monitored and photo-documented.

Findings - The findings show how new and emergent environmental management practices and routines were inherently contradictory to the situated and established culture within the projects. In fact project practices seemed to amplify the contradictions between environmental management and project management rather than mitigating them. As a result project members and organisation members strove toward different goals and foci. It is argued that management needs to create arenas where members from the two units can align practices and merge routines.

Practical implications - Aligning the permanent structures of the organisation with the temporary organising of practices and operational activities in projects is a challenge for the construction industry. A prevalent lack of fit between the organisation and its projects causes contradictions which negatively affect the way in which long-term environmental strategies and goals are understood and implemented in the project settings.

Originality/value - The system theoretical lens adopted in this study enables a holistic interpretation of complex and dynamic activities and the linking of the micro, the individual, to the macro, the organisational structure. By indicating some inherent and emergent contradictions between project practice and corporate environmental management, this paper contributes to an emergent field of research that focus on social practice in construction.

Keywords: project management, environmental management, project-based organizing, social practices, socio-cultural theory, activity theory
\end{abstract}

Article Type: Research paper 


\section{Introduction}

Within the construction industry, a common mode of organizing projects is by de-coupling activities from the main organisation and delegating responsibilities (Lundin and Söderholm 1995, Dubois and Gadde, 2002, Engwall, 2003). This projectification (Midler, 1995) nurtures a decentralized decision-making culture characterized by operational interdependence and organisational independence. These two features are often contradictory causing many of the problems in organizations, for example knowledge transfer (Styhre et. al., 2004), implementation of organizational change (Bresnen et. al., 2005), mismatches in management practices (Labuschagne and Brent, 2005) and resistance to innovation (Dubois and Gadde, 2002). However, how these contradictions emerge on the micro level and their effect on the macro level remains under-researched. One of the large challenges for project-based organizations today is to how to align organisational structures, such as environmental management systems (Gluch et al., 2009), with the temporary organisations and operational activities carried out in therein. These systems are often not fitted to the varying, local dynamic contexts of the projects, which results in resistance from project members to fully adapt, use or apply the established system in their day-to-day work (e.g. Styhre et al., 2004; Gluch, 2005; Dainty et al. 2006).

Yet, only a few articles in two leading journals of project management address environmental management issues in projects (c.f. Kwak and Anbari 2009, Crawford et al. 2006 and Themistocleous and Waerne, 2000); those that do, fail to address social and cultural aspects, instead advocating monitoring or controlling tools as solutions to environmental issues. Thus much of the current research and industry efforts addressing environmental management in projects seem to apply a normative theoretical perspective. This perspective views projects as 
instrumental for goal achievement and as entities that can be controlled and governed through a prescriptive and normative set of methods and techniques, an environmental management system being one such instrument. The methods and techniques developed based on this perspective pay little attention to the contradictions that prevail between the organisation and the situated local contexts of the individual projects. One of the few exceptions is Labuschagne and Brent's (2005) conceptual article which critiques the current project management practice for its rigid adherence to time-frames that are often inconsistent with core principles of sustainable development. In her longitudinal study of environmental professionals in construction Gluch (2009) concluded that environmental practices have not yet become embedded in project culture and practice, and that environmental discourse and project discourse have yet to be aligned. In line with suggestions by Ankrah et al (2008), there is a need to further investigate the complex relations between the logics of project-based organisations and that of corporate environmental performance and how to facilitate their alignment.

Using an activity theory lens this paper explores the interrelationship between project practice and environmental management at the micro level and discusses possible repercussions at the macro level. Based on results from two case studies, aimed at examining how environmental management and project practices unfolded on site, the paper discuss tensions that occur in the interface between human agents and material objects within a motive-directed, historically situated activity system, namely that of managing environmental issues in construction projects. 


\section{Activity theory}

Activity theory is an interdisciplinary approach that takes a system view of an activity such as the project or the environmental management view within a project as the case may be, and combines it with a subject view, i.e. takes on the perspective of one individual or group of individuals within the activity system (Engeström, 1999). Thus it bridges the individual subject and the socio-cultural structure. The development and transformation of an activity system over time are governed by the interactions between subject and object (i.e. motive of the activity) mediated by establish or emerging technical or semiotic tools and governed by rules and norms within a community of practice where there is a predetermined division of labour (see Figure 1).

Insert Figure 1 here

Figure 1: Classic model of an activity system (Engeström's seminal triangle)

To understand the interdependency of contextual factors and their influence on interaction we consider management of environmental issues in a construction project as an activity system

(Figure 2). The activity, managing environmental issues, is directed towards the object, fulfilling environmental demands stipulated in the project goals, which in turn are reciprocally formed and developed within the activity. The subject of this activity system is the environmental officials. These are persons appointed by the contractor to act as carriers of environmental information in and between various organisational units (Gluch, 2009; Gluch and Räisänen, 2009). According to activity theory, the subject works towards the object by using mediating instruments, such as technical tools and semiotic symbols, eg. environmental management systems, audits and policies. In addition to mediating the "doing of the job" these tools also regulate and legitimate interaction, they become institutionalised templates by which employees' social actions may be normalised and controlled (Räisänen and Linde, 2004). Consequently, as well as problematically, these are often modified implicitly or 
explicitly to suit different local contexts of use, which may give rise to conflicting communicative purposes and misunderstandings. The community is the group of people who work towards the same object, in our case the construction project team including client, contractor, sub-contractors and consultants. The division of labour is the horizontal and vertical distribution of work in this community. The activity is also framed by implicit and explicit rules, for example environmental demands and regulation, which control activity and interaction in the systems well as norms and routines.

Insert Figure 2 here

Figure 2: Managing environmental issues in construction projects as an activity system

\section{Method}

Case studies of two large international project-based construction companies (IntCon and NorCon) were conducted over the time period 2003-2004 (IntCon) and 2008-2009 (NorCon). The rationale for the choice of companies was that they had a strategically pro-active commitment towards greening; both were seen as trendsetters in the Swedish construction industry. Both companies were certified according to ISO14001 and followed the Global Reporting Initiative. The company group of IntCon also supported the United Nations Global Compact and had been listed on the Dow Jones Sustainability Index since 1999. Although ratings in sustainability indexes have been questioned as a suitable value standard for environmental performance (Cerin and Dobers, 2001), they nevertheless indicate that the top management of IntCon, and NorCon, have adopted an active environmental strategy. The focus of this study was two large ongoing civil-engineering-construction projects (Table 1): an inner-city motorway tunnel project, where IntCon was the contractor, and an inner-city railway bridge where NorCon was contractor.

Insert Table 1 here 


\section{Table 1: Case description}

In both projects the Swedish Transport Administration was the client. The project teams in the projects studied consisted of approximately of 120 persons (IntCon) and 50 (NorCon). To obtain an understanding of context-specific circumstances pertaining to environmental practices, such as corporate and project-specific environmental policies, demands and management systems, several site visits were made to enable observations of situated social interaction. The site visits, which varied from one day to four weeks, were photo-documented and generated extensive field notes. Each day of a visit ended with an informal interview with the environmental professional on site, which provided an opportunity for the researcher to get immediate feedback on observations and to verify interpretations. It also enabled an understanding of how beliefs, experiences, feelings and intentions are expressed in a specific setting. In addition, 15 (11 at IntCon and 4 at NorCon) weekly environmental site inspections were monitored and photo-documented. Furthermore organizational documents and drawings from the projects, the company intranets and management-control systems were reviewed. This methodological approach facilitated critical reflection and awareness of the interpretative activity that occurs when researchers attempts to understand the reality of what they are studying (Alvesson and Sköldberg, 2000).

Besides on-site observations, the study comprised, text analyses and semi-structured interviews with persons in the project organization as well as with persons belonging to the companies' corporate environmental organizations. These interviews, 20 altogether, lasted between one and two hours, and were recorded and transcribed in full. Moreover, one group interview was carried out at NorCon with four project members (two representing the contractor and two representing the client). At the group interview, also fully transcribed, the interviewees were confronted with preliminary results from the study and were given the opportunity to react and provide feedback. The transcribed material was coded using 
procedures recommended by Strauss and Corbin (1998) and Miles and Huberman (1984). The interview excerpts were emplotted (Czarniawska, 2004) by structuring them into sentences that were intelligible and made sense to the researchers. Key words, phrases and concepts were extracted, compared and contrasted, and then triangulated with the findings from similar analyses of the documents, the visual material and the field notes. The use of multiple sources, interviews, field observations, photo documentation, and text analyses enabled triangulation and provided a unique view on the project members' physical workspace and their social interaction. The following is based on an analysis of all the above mentioned empirical data.

\section{Results}

Considering managing environmental issues in construction projects as an activity system this section reports findings on the relationships and contradictions between the elements of the system.

\subsection{Subject: Environmental officials in construction projects}

A few environmental officials in administrative positions were forced to support up to 100 construction projects of various kinds, in various construction phases and with various environmental challenges. Due to their fragmented work duties they felt torn between and dependent upon two various organisational logics; the one of the project and the one of the permanent organisation, which the following quote illustrates.

“...I'm uncertain what to prioritize since I'm expected to do anything from training [employees] and carrying out environmental audits to supporting specific projects with detailed expertise help. I try to see the big picture... but it is difficult 
to make time for it when you have to follow up ten 'emergency' calls per day." (EC, NorCon)

The environmental officials were expected to act as support and filter of environmental knowledge to and from the projects. However, instead of being empowered by a knowledge advantage within a field emphasized as strategically important for the companies, the findings suggest that it created tensions since it challenged the site manager's traditional role as 'king on site'. More, their tasks were not considered operative in relation to the production with the consequence that although often entitled 'managers' they wielded no power in the project and thus unable to enforce actions in the project. As a consequence the environmental officials had to deal with situations where their beliefs and values conflicted with the productionfocused and time-pressed agenda of construction project practice. This resulted in them handling a balancing act between their assigned environmental mission and existing and institutionalized frames of project practice. Thus, these environmental officials were torn between their task to support necessary activities driven by societal changes and organisational needs and the limited time-resources of the projects.

\subsection{Division of labour: Project based organising}

The contractor organisations had similar structures with their main operations carried out in projects. Both companies had decentralized project organizations where each project was an autonomous unit with a project manager that was held accountable for actions and decisions taken within the project, for example financial results and environmental performance. Within each construction projects there was a strict chain of command, which meant that all project specific action points had to pass through the project manager before implementation. Sorted under a middle manager and in different locations, the environmental officials were not only decoupled from the project organization but also from each other leading to difficulties navigating between the interdependency and independency dimensions of the 
company. As a result they felt they had to be both generalist and specialist; on one hand they had to manage the difficulty of combining a strategic, policy-based, all-embracing and longterm perspective relevant for their company's whole business, and on the other hand they had to gain profound expertise within a targeted field of knowledge. This way of loosely coupling these environmental officials to both the environmental unit and the production-focused project organization resulted in them feeling marginalised, as illustrated by the following quote.

"It is low status to work with environmental issues, not swell enough; it is more prestigous to work as site manager, so you might be isolated and marginalised if you are too nit-picking. That's a balance act to handle." (EC, IntCon)

\subsection{Community: Cross-professional project communities}

While the project members were employed in the project they were also temporarily decoupled from the permanent organization, which they rejoined in between projects. The project members' perceived that the project had such tight time-frames that it did not leave room for networking activities outside the scope of the project. They experienced difficulties maintaining their contact nets. Additionally, there was no systematic or controlled exchange of environmental information between different projects within their company. Whether the members of the project organization got information from other on-going construction projects depended to a high degree on their personal network and on what kind of group they belonged to.

...you get a tip 'try call him or her, he/she might know', you always go throught someone you already have a relation to. (PM, IntCon)

As illustrated by the previous quote, the members' personal networks seemed to be a result of coincidences rather than a conscious effort to incorporate people with different knowledge and competences. Consequently most networks seemed to be homogenous groupings, i.e. a 
group of people that share profession, educational background, gender and age. Coherence in respectively group was partly created through this professional and disciplinary homogeneity; by sharing a common epistemology they possessed a community specific and shared common understanding and language.

Another consequence from the organizational distance between the permanent organization and the project organization was that it created mistrust towards the environmental organisation's ability to understand the project members' reality and work situation. This in turn nurtured a defensive attitude and a resistance towards suggestions of change in environmental routines.

\subsection{Object and outcomes: The project's environmental goals for an efficient and}

\section{sustainable construction}

The interviewees perceived the projects as labour-intensive, unique endeavours with defined goals constrained by strict time and cost frames. Both projects were also highly complex involving many project-specific environmental challenges, such as groundwater issues, noise and contaminated soil. However, even though environmental impacts caused by the construction process may extend beyond the project closure, the environmental boundaries were mentally restricted to the time span of the project. This meant that the environmental problems in the projects were regarded as 'momentary' in that they occured during the project's life span and when the project was finished so too were the problems. Consequently, project members' commitment to environmental issues was constrained by the project's time and space boundaries.

The priority of the construction projects, as stated by several interviewees, was to achieve the highest quality with the lowest input of financial resources within the given timeframe. This "rule" seemed to strengthen the notion that there was no space for preventive or proactive environmental actions. Some of the interviewees even considered such actions non-essential 
to achieving results within the stipulated financial and quality goals. As such the environmental concerns were often subject to tensions between the long-term strategies and norms of management and the short-term, time-pressed reality of projects.

\subsection{Rules: Environmental regulations and norms}

Both construction projects were initiated and driven by the national public the Swedish Transport Administration. In spite of the design-build contract was the clients' governance of the projects tighter than usual, the projects being regulated not only by the Swedish Environmental Code, but also by client-specific environmental demands in contractual agreements and documents. Due to the projects' environmental vulnerability, the client maintained strict control over the project. Environmental concerns were highlighted, but what issues were prioritised was regulated by the client's stipulated environmental demands. For example, detailed restrictions on levels of environmental impact on water, land, vegetation and air, levels of noise and vibrations, and handling of chemicals, material and waste were specified in a specific environmental plan. To control compliance the clients' had an assigned official that controlled environmental aspects on a regular basis. Their power in the project were strengthened by the fact that their attendance on site was associated with assessment and control.

Top managers from various construction companies, strive to surpass each other regarding environmental performance. It is embedded in bids, plans and so forth. Later, on site, when reality catches up, these ideas are toned down successively until it reaches a righteous level. (PM, NorCon)

As indicated in the quote, company specific environmental policies were embedded in the general project plan, a much more rigid plan that did not tolerate changes since these were considered to negatively affect the project practice and project result. In addition, the organisational distance between the environmental staff, which had developed and formulated 
many of the environmental policies and instructive texts, created mistrust among the project members towards the staff's ability to understand their reality and work situation. This nurtured a defensive attitude towards suggestions of changes in the environmental routines.

\subsection{Mediating instruments: Environmental management systems and audits}

The clients had project-specific environmental control programs that governed the work on site. These were flexible documents that could be frequently revised in accordance with regulatory or other changes. This flexibility meant project members had to continuously reinterpret the text, which gave the contractual document a symbolic role in the project in addition to its role of governing document.

Client project manager: You write and sign the contract before project start. Thereafter you interpret it. Site manager: But we have to optimize it so it suit project practice, make it manageable. A good example is the waste water treatment [...] were had to be more practical. Client project manager: yes, we disagreed a lot in the beginning on how we should interpret the documents regarding that. Our perceptions was rather different but when we sat down talking we found a, for us, satisfying agreement. Client EC: But it needs a good dialogue between parties. NorCon has demands and so do we, there are similarities but also differences, most of all in the nomenclature. (Group discussion NorCon)

To simplify routines, both companies had an integrated management system which to a high degree determined how these administrative tasks were distributed at an operational level. IntCon had a system that integrated environmental issues with those of quality and safety and NorCon integrated environmental issues with health and safety.

By concentrating environmental expertise to a few persons on the corporate staff level and distributing the administrative environmental work to officials with predominantly a building 
technology background, much reliance was placed on the internal web-based environmental management system (EMS) to guide the project members to act pro-environmentally. Relying on a web-based EMS required that environmental routines and procedures were standardized. This standardization of the environmental work, however, meant that environmental issues were controlled top-down with little flexibility. The discourse of the EMSs was governed by a management logic consisting of a rational, positivist linear process, while the daily acts of implementing environmental directives in the project were rife with uncertainty requiring rapid, ad hoc decisions that relied on previous knowledge, experience and affect. Apart from information included in internal audits, there were no formalized routines for the project organization to communicate environmental experiences from the projects to the rest of their company. Experience from the project thus remained within the project group resulting in a feeling that every new project starts from scratch.

“...you have to start from scratch in every project, start reading, 'what does this mean for this project, any new directives for consideration', and, well, it is not easily done..." (PM, NorCon)

Being distanced from the environmental unit, members of the project organization addressed their inquiries within their own established networks, which did not necessarily possess the relevant or updated knowledge. The use of ISO14001 as a governing instrument also demanded extensive reporting, which ran counter to the oral face-to-face communication culture that prevailed in the project setting. The reporting routines were therefore perceived as "foreign" and bureaucratic. Using standardized EMS bureaucratized environmental work to the extent that it is often perceived as administrative routines, maintaining a level considered as hygienic, and efforts other than the minimum considered as burdensome. 


\section{Discussion and conclusion}

In line with Arvidsson (2009), this study has revealed that tensions in project-based organisations are created due to contradictions at the interface between the organisation, the project and the client. To identify the nature of these tensions an activity theory lens was used, enabling a system view of managing environmental issues in construction projects within which the perspective of the subject the environmental officials was taken. It would have been possible to choose the perspective of another subject such as the project manager or the site manager. However, since the unit of analysis is the activity system, defined as "a conceptoriented, collective and culturally mediated human activity" (Cole and Engeström 1993), and not the individual, the identified contradictions would prevail, but the interpretations of the causes and effects may differ.

Moreover, analysing the interrelationship between all the elements of the activity systems prevents the researcher from falling into a dualistic or dichotomy trap. Furthermore, similarly to Gidden's (1984) concept of duality of structure, the activity system reproduces itself and has the capacity to transform. It is the tensions and contradictions within and between activity systems that drive a transformation and change. Therefore, to facilitate an alignment between project management and environmental management there must be transformation; and for there to be transformation, the contradictions and tensions within these activity systems need to be identified. The lighting-shaped arrows in Figure 3 illustrate the main contradiction spaces in the analysed activity system.

Insert Figure 3 here

Figure 3: Tensions caused by contradictions between central elements of the activity system 
As Dubois and Gadde (2002) and Lindkvist (2004) have argued, the loose coupling between temporary project organising and the permanent organization has over time established an almost institutional disconnect between the two entities. The project activity system, with its traditional reputation of goal-oriented uniqueness, has a short-term product time and product focused goal-orientation while the organisation activity system has a long term overall productivity and performance goal-orientation (Persson 2005). In this system, the projects are mediating instruments toward that goal. The managing of environmental issues activity system is caught in the middle of these two decoupled systems. The environmental officials are located in the permanent organisation to which they are accountable and the mediating instruments of which they mainly use. Simultaneously they support the projects and filter environmental information, rules and regulations down stream and report upstream, back to management. Environmental work is thus governed by a top-down controlled environmental management approach, but carried out by environmental officials who do not belong to the project community and who do not carry any decision-making mandate in the permanent organisation nor in the projects where these decisions were to be operationalised. There is thus a serious misfit between the activity system of the environmental officials and that of the decentralized and autonomous decision-making culture of the project. The activity systems also used different mediating semiotic tools e.g. discourses and genres mostly in document form, which distanced these official from the talking culture of the project.

This misfit implicated the object/motive toward which the subjects in the two activity systems strove: the object of the officials (Fig. 2) was the fulfilment of corporate as well as project specific environmental demands while the project objective was the completion of the project on time and according to stipulated budget. Environmental problems in the project were regarded as 'momentary' and 'unique' problems subject to negotiation, i.e. they occurred 
during the project and were resolved for the project. Once the project was terminated so were the environmental issues. Even though environmental impacts caused by the construction process were likely to exceed the project closures, the contained environmental boundaries restricted to the time span of the project have become culturally and cognitively ingrained in project members behaviour. As pointed out by Labuschagne and Brent (2005) this absolves them from taking a holistic and long-term perspective. The projects tended to create their own self-regulating environmental rules resulting in the project community's motives for behaving pro-environmentally being biased towards short-term performance. Flexibility and innovation in such an environment were quite naturally constrained by project imperatives and maintained through the bracketing of the project (Kreiner, 1995). Project member's abilities and motivation to perceive and handle long-term environmental impacts were thus curtailed. An attempt to initiate transformation in the management of environmental issues in the projects' activity system and generate proactive and long-term environmental behaviour was to embed triggers in the project plans and contractual documents. However, the project plans were designed based on actors' presumptions about the future at the time of the document inscription. Moreover, project plans simplify the world by making the future explicit so that precise definitions of boundaries, tasks, resources and their allocation are enabled, while neither the future nor the natural environment remain static. Generating too much trust that environmental aspects will be included in project plans and other specifications seems to result in green truths based on past experiences and institutionalized in the organization.

Because of the decentralised nature of construction companies, business relations have by tradition have been built on personal contacts (Eccles, 1981). An anonymous centralized environmental unit and EMS governance as in the current cases, therefore, suffered from the "not invented here" syndrome, which was strengthened by the geographical, social and 
cultural distance between the environmental officials and the projects. In the current misaligned activity systems fulfilling the administrative routines predicated by the EMS instrument risks becoming the object of managing environmental issues in the projects rather than fulfilling the project's environmental goals.

To sum up, applying an activity theory lens has proved to be a viable framework for analysing contradictions between institutionalised black-boxed project practice and emerging environmental management practice. A possible enabler of transformation lies in breaking the "isolation" between the organizational units within project-based organizations by finding ways where environmental management and project management professionals can join forces to raise awareness of the contradictions that are hidden at the boundaries and within the activities systems of their workplaces. Top management can encourage project organisation members to participate in a variety of networking and dialogue activities. Top management can also nurture the creation of communicative arenas where people can meet and exchange information and knowledge. These endeavours also need to be anchored at all levels of the organisation to enable initiatives to move from the bottom up as well. However, to make this work two things have to be considered. Firstly, it is important to consider the communicative culture of the organization so that fruitful and equal discussions may be held. Secondly, for equality to reign vis-à-vis management, the members of the environmental unit need to be invested with the authority to act so that environmental issues may gain their rightful legitimacy within the organization.

\section{References}

Alvesson, M., Sköldberg, K. (2000) Reflexive Methodology - New vistas for qualitative research, Sage, London. 
Ankrah N.A., Proverb D., Debrah Y. (2008) Factors influencing the culture of a construction project organisation: An empirical investigation. Engineering, Construction and Architectural Management 16(1): 26-47.

Arvidsson N. (2009) Exploring tensions in projectified matrix organisations. Scandinavian Journal of Management 25: 97-107.

Bresnen M., Goussevskaia A., Swan J. (2005) Implementing change in construction project organizations: exploring the interplay between structure and agency. Building Research and Information 33(6): 547-560.

Cerin P., Dobers P. (2001) What does the performance of Dow Jones sustainability group index tell us? Eco-management and Auditing 8(3): 123-133.

Cole M., Engeström Y. (1993) A cultural-historical approach to distributed cognition. In G. Salomon (Ed) Distributed cognitions: Psychological and educational contribution. Cambridge University Press, NY: 1-47.

Crawford L., Pollack J., England D. (2006) Uncovering the trends in project management: Journal emphases over the last 10 years. International Journal of Project Management 24:175-184.

Czarniawska, B. (2004) Narratives in social science research, Sage, London.

Dainty, A., Moore, D., Murray, M. (2006) Communication in Construction - theory and practice. Taylor \& Francis, NY.

Dubois A., Gadde L.E. (2002) The construction industry as a loosely coupled system: implications for productivity and innovation. Construction Management and Economics 20: 621-631.

Eccles, R.G. (1981) The quasifirm in the construction industry. Journal of Economic behaviour and Organization 2: 335-357. 
Engeström, Y. (1999) Activity theory and individual and social transformation. In Perspectives on Activity Theory (eds Engeström, Miettinen, Punamäki), Cambridge University Press.

Engwall M. (2003) No project is an island: linking projects to history and context. Research Policy 32: 789-808.

Giddens A. (1984) The constitution of society: outline of the theory of structuration, University of California Press.

Gluch P. (2005) Building Green: Perspectives on environmental management in construction, diss. thesis, Chalmers University of Technology.

Gluch P. (2009) Unfolding roles and identities of professionals in construction projects exploring the informality of practices. Construction Management and Economics 27 (10), 959-968.

Gluch P., Brunklaus B., Johansson K., Lundberg Ö., Stenberg A-C., Thuvander L. (2009) Environmental attitudes, Management and Performance. In Performance Improvement in Construction Management (Eds. Atkin B. and Borgbrant J.), Taylor and Francis, London.

Gluch P., Räisänen C. (2009) Interactional perspective on environmental communication in construction projects. Building Research and Information, 37(2), 164-175.

Kreiner K. (1995) In search of relevance: Project management in drifting environments. Scandinavian Journal of Management 11(4): 335-346.

Kwak Y.H., Anbari F. (2009) Analyzing project management research: Perspectives from top management journals. International Journal of project Management 27: 435-446.

Labuschagne C., Brent A.C. (2005) Sustainable project life cycle management: the need to integrate life cycles in the manufacturing sector. International Journal of Project Management 23: 159-168. 
Lindkvist L. (2004) Governing project-based firms: Promoting market-like processes with hierarchies. Journal of Management and Governance 8: 3-25.

Lundin R.A., Söderholm A. (1995) A theory of the temporary organization. Scandinavian Journal of Management 11(4): 437-455.

Midler C. (1995) "Projectification" of the firm: The Renault case. Scandinavian Journal of Management 11(4):363-375.

Miles M.B., Huberman A.M. (1984) Qualitative Data Analysis: A Sourcebook of New Methods, Sage, London.

Persson S. (2005) Toward enhanced interaction between engineering design and industrial design, diss. thesis, Chalmers University of Technology.

Räisänen C., Linde A. (2004) Technologizing Discourse to Standardize Projects in Multiproject Organizations: Hegemony by Consensus? Organization, 11(1), 101-121.

Strauss A.L., Corbin J. (1998) Basics of Qualitative Research, $2^{\text {nd }}$ ed., Sage, Thousand Oaks, CA.

Styhre A., Josephson P-E., Knauseder I. (2004) Learning capabilities in organizational networks: case studies of six construction projects. Construction Management and Economics 22: 957-966.

Themistocleous G., Wearne S.H. (2000) Project management topic coverage in journals. International Journal of Project Management 18: 7-11. 


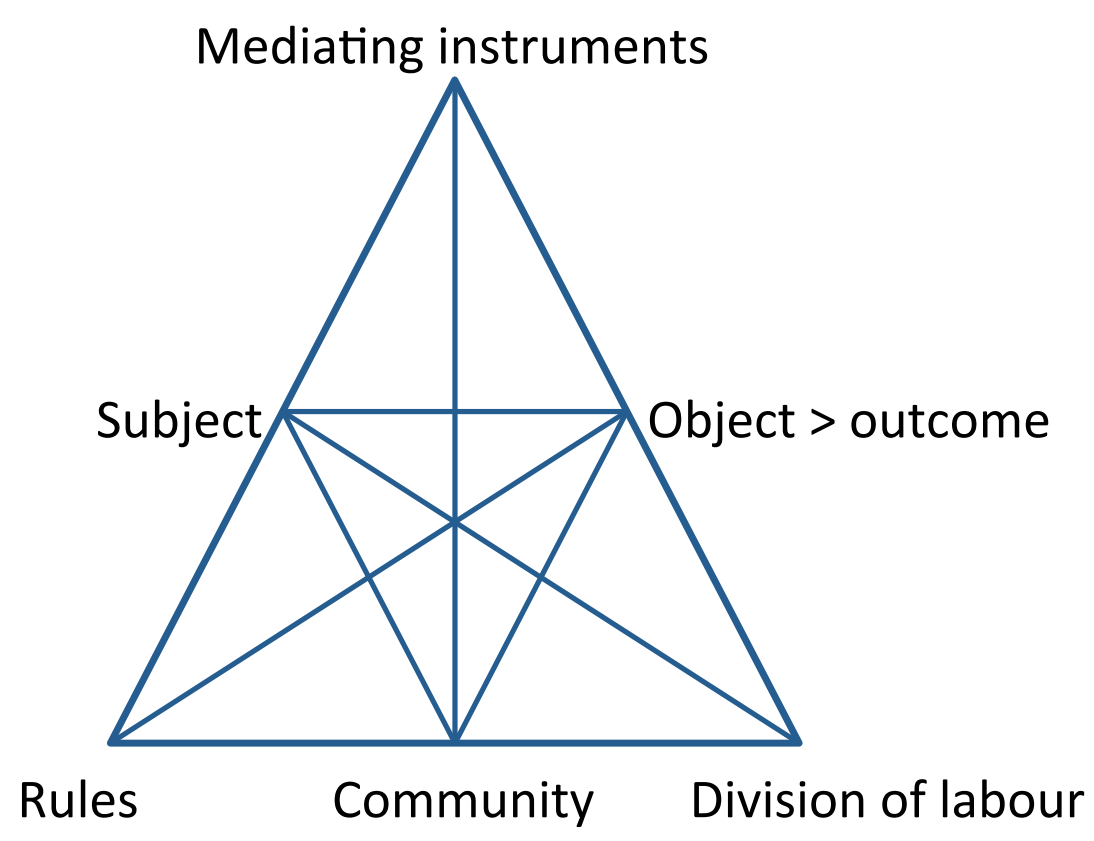

Figure 1: Classic model of an activity system (Engeström's seminal triangle) 


\section{Environmental}

management

tools, eg EMS

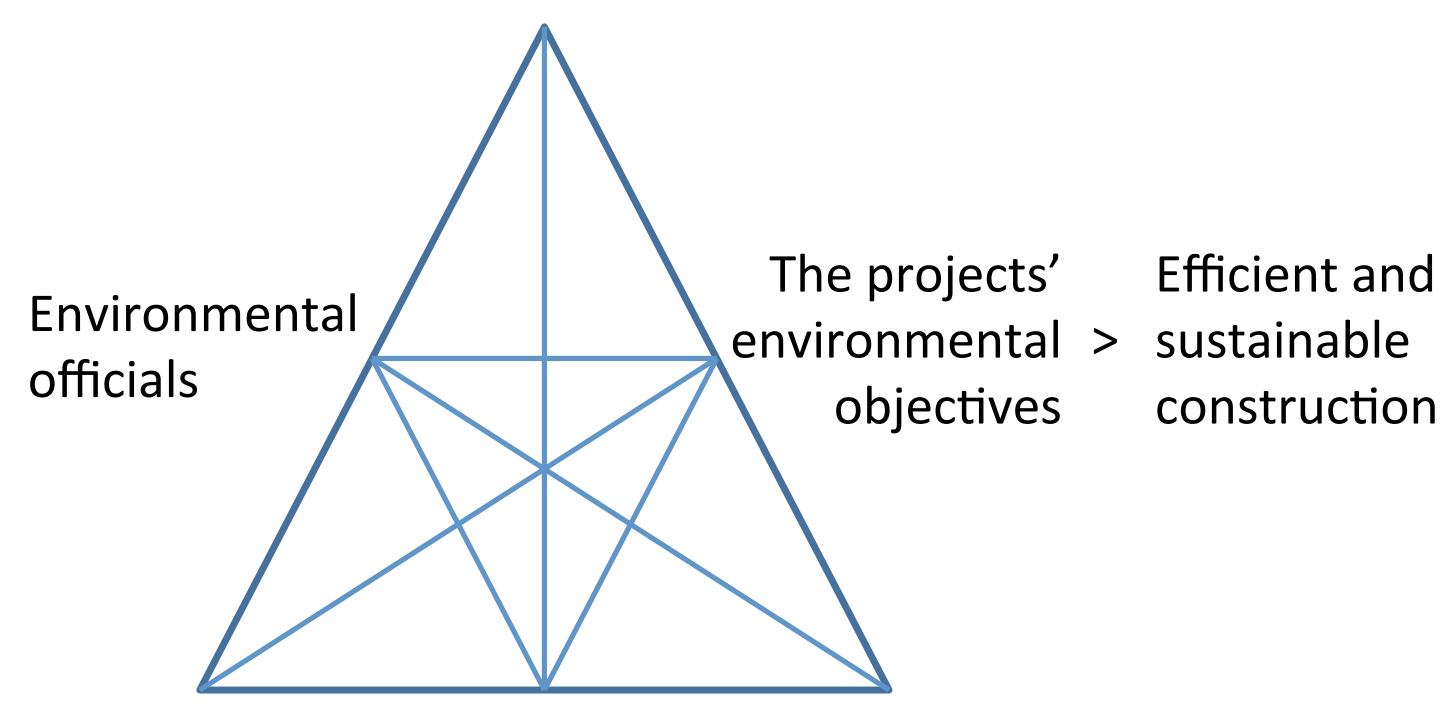

Environmental Construction Project based

regulation project organising

and norms community

Figure 2: Managing environmental issues in construction projects as an activity system 


\section{Environmental}

management tools, eg EMS

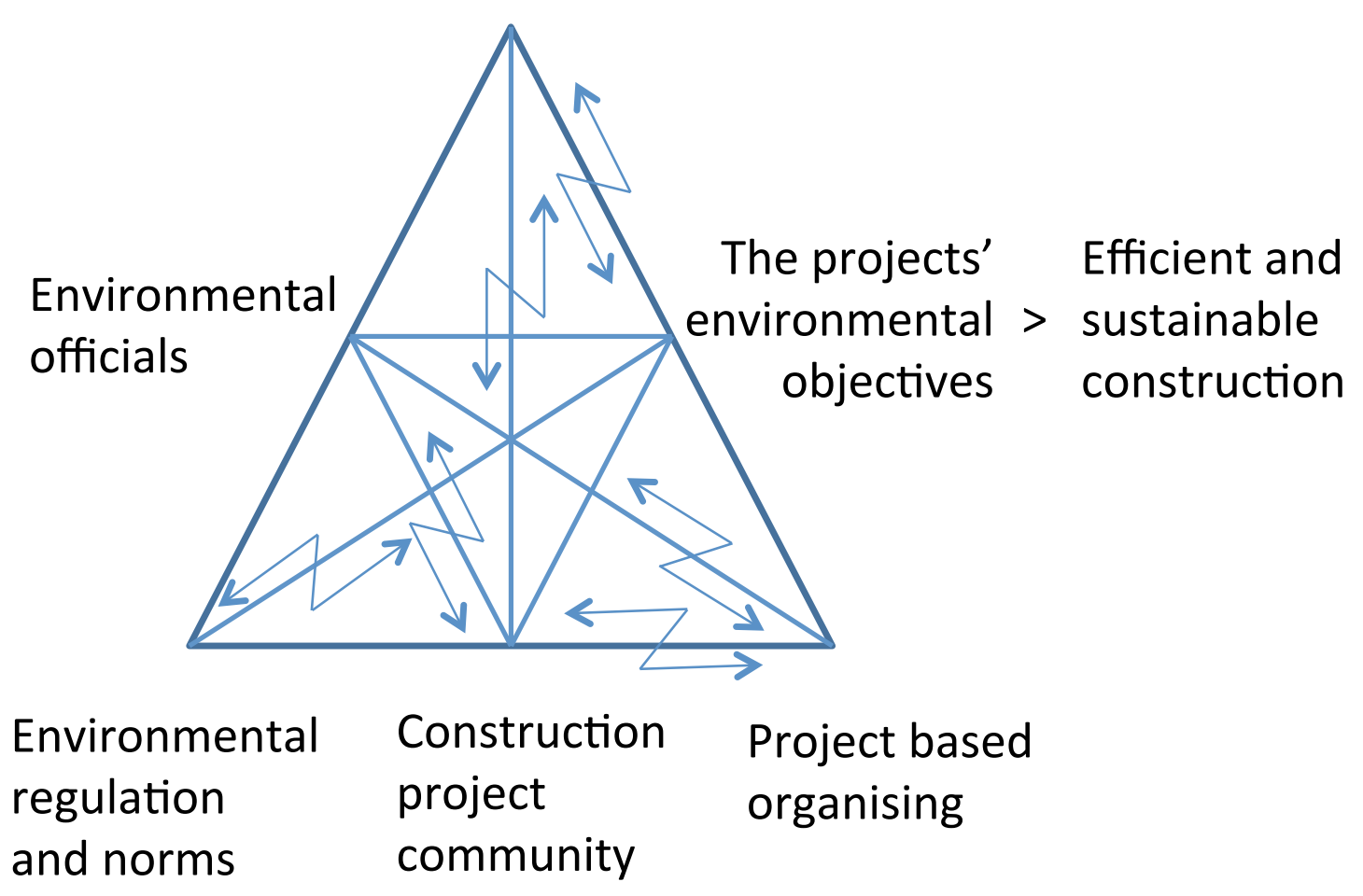

Figure 3: Tensions caused by contradictions between central elements of the activity system 